\title{
Mouthguards: does the indigenous microbiome play a role in maintaining oral health?
}

\author{
Purnima S. Kumar ${ }^{1 *}$ and Matthew R. Mason ${ }^{2}$ \\ ${ }^{1}$ Division of Periodontology, College of Dentistry, The Ohio State University, Columbus, OH, USA, ${ }^{2}$ Division of Biosciences, \\ College of Dentistry, The Ohio State University, Columbus, OH, USA
}

OPEN ACCESS

Edited by:

Egija Zaura,

Academic Centre for Dentistry

Amsterdam, Netherlands

Reviewed by:

Gena D. Tribble,

University of Texas Health Science

Center at Houston, USA

Alex Mira,

Center for Advanced Research in

Public Health, Spain

*Correspondence:

Purnima S. Kumar,

Division of Periodontology, College of Dentistry, The Ohio State University, 4111 Postle Hall, 305 W. 12th Ave.,

Columbus, OH 43210, USA

kumar.83@osu.edu

Received: 25 June 2014 Accepted: 25 March 2015 Published: 06 May 2015

Citation:

Kumar PS and Mason MR (2015) Mouthguards: does the indigenous microbiome play a role in maintaining

oral health?

Front. Cell. Infect. Microbiol. 5:35. doi: 10.3389/fcimb.2015.00035
The existence of symbiotic relationships between bacteria and their hosts in various ecosystems have long been known to science. The human body also hosts vast numbers of bacteria in several habitats. Emerging evidence from the gastro-intestinal tract, genito-urinary tract and respiratory indicates that there are several health benefits to hosting a complex and diverse microbial community. Bacteria colonize the oral cavity within a few minutes after birth and form stable communities. Our knowledge of the oral microbiome has expanded exponentially with development of novel exploratory methods that allow us to examine diversity, structure, function, and topography without the need to cultivate the individual components of the biofilm. The purpose of this perspective, therefore, is to examine the strength of current evidence supporting a role for the oral microbiome in maintaining oral health. While several lines of evidence are emerging to suggest that indigenous oral microbiota may have a role in immune education and preventing pathogen expansion, much more work is needed to definitively establish whether oral bacteria do indeed contribute to sustaining oral health, and if so, the mechanisms underlying this role.

Keywords: commensal, oral, health, beneficial, ecosystem, host-bacterial interactions, inter-microbial interactions

\section{Homo sapiens as a Member of the Bacterial Kingdom}

Bacteria predate humans on Earth by at least three billion years (Beraldi-Campesi, 2013); and have successfully survived the vicissitudes of drastic temperature changes, earthquakes, volcanic eruptions, and the advent of new species, evolving with each age and era. Along with their own evolution, these organisms have played a major role in shaping eukaryotic evolution, both as endosymbionts and as ectosymbionts (Pace, 1997). As Homo sapiens evolved, these organisms coevolved with their host to such an extent that the human body is considered a super-organism consisting of functionally, metabolically, and spatially integrated bacterial and human cells (Ley et al., 2008). Modern-day man plays host to at least 10 times as many bacterial cells as human cells (Sleator, 2010). In fact, it might be more logical to view the human being as an inhabitant of the microbial world, rather than the reverse. Given this perspective, it is important to acquire a comprehensive understanding of the bacteria that inhabit us, and their collective genes (the human microbiome).

Recent large-scale public, private and crowd funded initiatives such as the Human Microbiome Project (HMP) (Human Microbiome Project Consortium, 2012), Metagenomics of the Human Intestinal Tract (MetaHIT) (Li et al., 2014), and UBiome (Costandi, 2013) have allowed us to 
explore human-microbial and inter-microbial interactions to better understand the implications of hosting our microbial fellow travelers. Through these and other studies, we are beginning to learn not only how these bacteria are acquired and their colonization dynamics, but also how diverse factors, such as host genotype, host environment and host development shape these communities (Costello et al., 2009; Zaura et al., 2009; Kumar et al., 2011; Greenblum et al., 2012; Mason et al., 2013).

\section{The Oral Microbiome as an Ecosystem}

The term ecosystem was introduced by Arthur Roy Clapham to describe a community of living organisms along with their living and non-living environment, interacting as a system and linked to each other through energy transfer and nutritional flow (Blew, 1996). Based on this definition, humans may be considered a collection of microbial ecosystems (Prosser et al., 2007). The body provides several habitats for colonization-the oral cavity, nasopharynx, gastrointestinal tract, vagina, and skin-each with differing topographical, nutritional, physical, and environmental characteristics. For example, the nasopharynx, gastrointestinal tract, and vagina are all non-keratinized mucosal environments with varying degrees of oxygen tension and $\mathrm{pH}$ levels. In contrast, the skin provides an aerobic, keratinized epithelial surface for microbial inhabitance.

The oral cavity is a unique environment in that it is divided into several smaller habitats-biotic habitats such as the non-keratinized buccal mucosa, the keratinized mucosa of the tongue and gingiva, the subgingival sulcus, and abiotic surfaces such as the enamel, dental restorations, and dental implants. At any given time, over twenty billion organisms can be found in this environment (Loesche, 1982), representing nearly 700 different species (Aas et al., 2005). Since the oral cavity is an open ecosystem, several of these species may be allochthonous members (transient visitors), however, certain organisms colonize these surfaces (autochthonous constituents) soon after birth and form organized, cooperating communities within these niches, called biofilms (Savage, 1977). It has been shown that, in certain niches (for example the tooth surface), this colonization is a very organized event with a specific temporal and spatial sequence (reviewed by Kolenbrander et al., 2006), and can be driven by environmental and host-determined factors (Mason et al., 2013). The traditional view of these biofilms is that they are comprised of species that live in equilibrium with the host immune defenses-the so-called "commensals." However, commensalism, by definition, is a symbiotic relationship that benefits one species without harming the other. The implications of this are that the oral cavity hosts a diverse microbial community with no major benefits to the host. Since such onesided relationships are not the norm in nature, the purpose of this perspective is to examine the currently available evidence on the health benefits of hosting a complex oral microbial ecosystem.

\section{Evidence for Habitat Specific Colonization as a Health Benefit}

A central characteristic of an ecosystem is habitat-specific colonization. For example, a wetland consists of several habitats extending from tidal creeks into low marshes and climax maritime forests, each with a specific community of flora, fauna, and microflora (Cherry, 2011). According to the physiological hypothesis, habitat specificity offers several benefits to the colonizing species, ranging from predator protection to mating to nutritional abundance (Smiley, 1978). Thus, organisms that require few host-associated benefits occupy a wide range of habitats (generalists), while evolution dictates the emergence of specialist species that are confined to a single or narrow range of habitats. Evidence is emerging from microbial ecological systems that habitat specificity also allows a species to regulate gene expression and modify its phenotype to segregate its niche (reviewed by Young, 2006). For example, an organism determines its shape by complex algorithms that take into consideration diverse factors such as nutrient access, cell division and segregation, attachment to surfaces, passive dispersal, active motility, polar differentiation, the need to escape predators, and the advantages of cellular differentiation.

Ecologically, habitat specificity offers several benefits to the hosting species. The presence of certain algal species is important to enhance the calcifying and metabolic activities of coral-reef building anthozoans; and therefore, both species maintain their habitat specificity in all types of environments. In other marine environments, bacteria within specific habitats protect their hosts from fungal infections, detoxify host metabolites, and inhibit epibionts (White and Torres, 2009).

It is well-known that human microbial communities vary significantly by habitat. The oral microbiome is distinct from that of the gut, the ear, and the nasopharynx, even though it is geographically connected to these habitats through the esophagus, Eustachian tubes, and fauces, respectively (Frank et al., 2003; Heinemann and Reid, 2005; Flint et al., 2007; Costello et al., 2009). Within the oral microbiome, structural, spatial, functional, and compositional characteristics of supragingival and subgingival biofilms are remarkably different (Socransky and Manganiello, 1971), as are the characteristics of mucosal and tongue biofilms when compared to these tooth-related habitats (Ximenez-Fyvie et al., 2000; Socransky and Haffajee, 2005; Zaura et al., 2009). For example, Streptococcus mitis, S. pneumoniae, and Granulicatella adiacens appear to be generalists in the oral ecosystem, occupying both dental and mucosal habitats; while Rothia dentocariosa, Actinomyces spp., S. sanguinis, S. gordonii, and $A$. defectiva preferentially colonize teeth, and Simonsiella muelleri only colonizes the hard palate (Aas et al., 2005). Even with the same environment (supragingival or subgingival), bacterial composition varies considerably based on tooth location and site (Sreenivasan et al., 2010; Simon-Soro et al., 2013a). For example, abundances of $C$. gingivalis and $S$. sanguinis correlate with lower incisors and canines, while Actinomyces naeslundii 2 (also known as $A$. oris) demonstrates a positive association with upper anteriors (Haffajee et al., 2009).

While evidence demonstrates the existence of habitat-specific microbial communities in the oral cavity, the benefits conferred by this spatial segregation to community members and the implications of this phenomenon for oral health have not been as well-studied. Most of our current knowledge comes from investigations of specific species, for example, Porphyromonas 
gingivalis (iron availability and anaerobiosis), Fusobacterium nucleatum ( $\mathrm{pH}$, anaerobiosis, etc.) and oral Streptococci (salivary glycans, simple carbohydrates, etc.). Investigating the effect of spatial segregation on community membership and function would be critical to elucidating the role played by distinct bacterial consortia in the etiology of site-specific diseases such as caries and periodontal disease.

\section{Evidence for Colonization Resistance as a Health Benefit}

One of the most important benefits a resident microbial community can offer to the host is resistance to invasion. In environmental ecology, invasion is defined in the process by which an exogenous species establishes itself within a resident community (Shea and Chesson, 2002). However, many human diseases are polymicrobial infections, sometimes occurring due to an overgrowth of opportunistic resident species, suggesting that "pathogens" are already present in a health-compatible environment. Hence, in human microbial ecosystems, several lines of evidence have demonstrated that the role of indigenous bacteria in controlling pathogenic colonization is by preventing pathogen expansion rather than by retarding exogenous acquisition (van der Waaij et al., 1971; Winberg et al., 1993; Drenkard and Ausubel, 2002; Wardwell et al., 2011). Disruption of resident communities with antibiotics is consistently associated with increased colonization by pathogenic species or pathologic overgrowth of certain commensals, leading to disease (Pavia et al., 1990; Pepin et al., 2005; Adams et al., 2007). This effect has been seen in the gut, vagina, and oral cavity (van der Waaij et al., 1971; Winberg et al., 1993; Ubeda et al., 2010). In certain cases, loss of colonization resistance can lead to take-over of the community not only by pathogenic bacteria, but also by higher order organisms, for example Candida, in both the vagina and the oral cavity (Budtz-Jörgensen, 1990; Spinillo et al., 1999). On the other hand, replenishing the resident microbiome using probiotics has been shown to reverse the effects of antibiotic-induced pathogen disease in the urinary tract, gut, and the dentition (Madden et al., 2005; Whorwell et al., 2006; Amdekar et al., 2011; Culp et al., 2011). Also, recent evidence from fecal biotherapy studies have demonstrated that restoring a native commensal population has been able to reverse pathogenic Clostridium difficile infection (Gough et al., 2011).

Although early evidence from non-microbial ecosystems indicated that highly diverse communities (as defined by those with more types of species) resisted exogenous invasion better than communities with fewer species (Fargione and Tilman, 2005), evidence has been emerging since then to indicate that species abundance (that is, the relative levels of each species within the community) plays a very important role, in some instances, a greater role than does species-richness (Kumar et al., 2006, 2011; Griffen et al., 2012). The first line of defense in colonization resistance is niche saturation, an ecological phenomenon where a certain number of species dominate the community, and resist colonization by pathogenic organisms (Brockhurst et al., 2007). This saturation phenomenon helps create a barrier for exogenous colonization (van der Waaij et al., 1971), prevent pathogen expansion (Gao et al., 2014), and maintains community stability, resulting in mucosal health (Abt and Pamer, 2014).

Change in species diversity is a hallmark of many bacterial dysbiotic conditions; certain diseases like bacterial vaginosis (Fredricks et al., 2005; Oakley et al., 2008), are associated with increase in diversity, while some others, for example, respiratory tract infections (influenza and bacterial pneumonia), and certain gut infections (H. pylori and C. difficile) are associated with decreased diversity. Interestingly, within the oral ecosystem, while periodontal diseases are associated with an increase in diversity (Loe et al., 1965; Listgarten, 1976; Loesche and Syed, 1978), dental caries is associated with a decrease in diversity (Simon-Soro et al., 2013b). Thus, any deviation from the stringently controlled diversity that is associated with health appears to result in disease.

In summary, literature is emerging in the gut, respiratory, urinary, and vaginal microbiomes supporting the role of colonization resistance as a health benefit. These lines of evidence include (i) pathogen colonization resulting from loss of resident microflora following antibiotic therapy, (ii) reversal of pathogen colonization by probiotic use, (iii) pathogen acquisition following changes in indigenous diversity, and (iv) reversal of pathogenic colonization following bacterial remediation (fecal transplants). Within the oral cavity, the lines of evidence have not been as robust or defined; possibly because bacteria implicated in the etiology of periodontal diseases and dental caries are already present within the health-compatible microbiome (pathobionts) (Jiao et al., 2014). Thus, the role of the oral microbiome in maintaining health may be more to prevent pathogen expansion rather than preventing exogenous acquisition. It is important to recognize the uniqueness of this ecosystem, and target research toward examining the implications of microbial homeostasis in an open, polymicrobial ecosystem.

\section{Importance of Temporal Stability, Resistance, and Resilience in Health}

In any ecosystem, three factors contribute longitudinally to health-the ability of the ecosystem to maintain its diversity, structural, and functional framework, as well as its ability to rebound from episodes of disturbance. In the pharyngeal microbiome, loss of temporal stability has been suggested the most proximal cause for the development of respiratory tract infections (Gao et al., 2014). Gao et al. have reported that patients with cystic fibrosis (CF) are the most susceptible to secondary infections, followed by chronic obstructive pulmonary disease (COPD) and asthma. Interestingly, the levels of Bacteroidetes were found to be lowest in CF, followed by COPD and asthma. Thus, it is hypothesized that as the protective "cover" offered by Bacteroidetes decreases, pathogenic Proteobacteria expand from their normal niche in the oropharynx and advance down the respiratory tract; their habitat-specificity being altered by the lack of competition in the "new" niche.

Oral bacteria are acquired at birth, and their colonization in the pre-dentate infant is dependent both on host genotype and on nutrition (van Steenbergen et al., 1997; Kobayashi et al., 2008). Following the development of dentition, a stable 
microbiome is acquired that persists into adulthood. There is evidence that bacterial composition remains stable over long periods of time (Rasiah et al., 2005; Kumar et al., 2006), even following routine dental prophylaxis and recolonization (reviewed by Teles et al., 2013). Less is known about resilience of oral bacterial communities. We have recently demonstrated that subgingival and marginal biofilms return to nearly $90 \%$ of their original compositional structure following repeated episodes of gingivitis (Joshi et al., 2014) in never smokers, but that this resilience is lost in current smokers. The host response to this "newer" microbiome is a higher than before pro-inflammatory response, suggesting that repeated episodes of gingivitis in smokers may present a higher risk for disease than in nonsmokers.

\section{The Role of Bacterial Cooperativity in Resistance, Stability, and Resilience of Microbial Communities}

Colonization resistance and temporal stability are mediated through several inter-bacterial and host-bacterial interactions. This section will focus on what we currently know about how bacterial interactions allow species to selectively colonize, survive, and thrive in a habitat. Bacteria within human ecosystems depend upon each other for structural and metabolic cooperativity; a constraint that dictates their relative proportions within the community (Wintermute and Silver, 2010). This mutual symbiosis is one important factor in maintaining the abundances of genetically distinct species in a community and therefore, contributes significantly to microbial homeostasis. Bacterial colonization of a habitat begins through non-random species selection. This non-random event is facilitated by several inter-bacterial interactions, for example, nutritional syntrophy, coaggregation, antagonism, and communication.

Syntrophy or nutritional symbiosis [also known as crossfeeding (from Greek for eating together)] is one of the oldest mechanisms facilitating the formation of polymicrobial communities. Work from the gut has provided insight into the role of symbionts in shaping the evolution of microbial components of this microenvironment through lateral gene transfer. For example, gut dwelling Bacteroidetes have used this mechanism to vary their cell surface, sense their environment, and harvest nutrient resources present in the distal intestine (Xu et al., 2007).

In oral biofilms, this phenomenon is not as well-characterized, however, it has previously been shown that Veillonella and Streptococcus, two of the earliest and most abundant genera to colonize oral biofilms, share a nutritional syntrophy, in that the Veillonellae utilize the lactate that is produced by the Streptococci as a food source (Kuramitsu et al., 2007). Also, Streptococcus sanguis and S. oralis exhibit synergy in degrading mucins, thereby allowing efficient utilization of host glycopolysaccharides for nutrition (Van der Hoeven and Camp, 1991).

Coaggregation among the early colonizers is another important mechanism that controls the composition of tooth-associated biofilms. Streptococci, due to the presence of Antigen I/II receptors for salivary agglutinin glycoprotein, are the primary orchestrators of coaggregation events. Not only do they bind to salivary pellicle, dentin and collagen, but also, the presence of these receptors is essential for acquisition of another early colonizer $A$. naeslundii (Kolenbrander et al., 2006). Also, incorporation of the bridge species, F. nucleatum into the biofilm has been shown to be dependent on A. naeslundii (Periasamy et al., 2009). Recent evidence suggests an important role for Candida species in maintaining oral health, by providing metabolic, chemical, and physical support for colonization by certain bacteria (reviewed by Krom et al., 2014).

Antagonism is the collective ability of the normal microbiota to prevent colonization of exogenous and opportunistic pathogens. In the gut, for example, the presence of butyrate, a short chain fatty acid produced as a metabolic byproduct by some commensals, down regulates expression of virulence genes in Salmonella spp. (Gantois et al., 2006) The earliest reports of bacterial antagonism in the oral environment came from Hillman and Socransky, who demonstrated that plaque from periodontally healthy individuals was capable of inhibiting growth of certain periodontal pathogens (Hillman et al., 1985). Evidence has shown some commensal oral bacteria have antagonistic activity against periodontopathogens (van Essche et al., 2013). Specific examples of bacterial antagonism by means of producing metabolites in the oral cavity include hydrogen peroxide production by streptococcal species to inhibit growth of periodontopathongens (Hillman et al., 1985) and lactic acid production to prevent Pseudomonas aeruginosa incorporation into the biofilm (He et al., 2011). Evidence has shown Streptococci exhibit antagonistic properties toward certain Staphylococci in the oral cavity as well (Krzeminski and Raczynska, 1993). Some indigenous microbiota take colonization resistance a step farther by producing specific antibiotics, such as bacteriocin production in strains of Streptococcus salivarius, that act on specific pathogens to prevent their colonization of the community (Sanders and Sanders, 1982). This mechanism has also been studied in response to cariescausing bacteria (reviewed by Kreth et al., 2009). S. sanguinis and $S$. gordonii produce hydrogen peroxide, a chemical that decreases proliferation of $S$. mutans in a cell-density independent manner. $S$. oligofermentans utilizes the lactic acid produced by $S$. mutans to generate $\mathrm{H}_{2} \mathrm{O}_{2}$.

Microbes are also in direct competition for available nutrients, and in many cases the indigenous microbiota create food webs where one species end product is used by another species (Ley et al., 2006). This sequestration of nutrients by the indigenous microbiota is designed to make the colonization of nonindigenous species very difficult (Freter et al., 1983). In the gut for example, the nutrient depletion provided by the indigenous microbiota plays a role in suppressing $C$. difficile overgrowth (Wilson and Perini, 1988).

In summary, structural, metabolic, and chemical interactions between bacteria play an important role in maintaining community hemostasis by supporting the critical proportions of these species in a health-compatible microbiome. The evidence for health benefits of these interactions has been exemplified in the caries literature. 


\section{Educating the Host Immune System as a Health Benefit}

Evidence is emerging to suggest that lack of a bacterial stimulus can lead to the development of atopy, a genetic predisposition to general allergic reactions. Several mechanisms have been postulated to explain this connection, with the "Hormetic Theory" being the most widely accepted (Bukowski and Lewis, 2007). The Hormetic theory suggests that exposure to a commensal bacterial flora during early years of life serves to educate the immune system, enabling it to distinguish between pathogens and host proteins. Children with low levels of the commensals Lactobacillus and Bifidobacterium demonstrate a greater predisposition to allergies (Bjorksten et al., 2001; Sepp et al., 2005). Further, administration of prenatal Lactobacillus $G G$ to mothers of high-risk infants decreased the incidence of atopy (Kalliomaki et al., 2001).

Recent evidence suggests the human microbiome is also capable of directly stimulating various components of the innate and adaptive immune responses. Much of this evidence comes from studying the gut which houses a complex and diverse microbial community (Hooper and Gordon, 2001; Ley et al., 2006; Neish, 2009). The first line of immunity to foreign species is the physical barrier of the epithelial tissue. In the gut, the gutassociated lymphoid tissue (GALT), is severely underdeveloped in germ-free mice, but undergoes enlargement when exposed to antigen (Pollard and Sharon, 1970), thus suggesting a role of host-microbe interactions in the initial development of early immunity. Additional animal studies involving germ-free model systems demonstrate greater antigen transportation compared to animals with a resident biofilm (Sudo et al., 1997). Further, germfree animals mount a severe immune response when exposed to commensal bacteria.

\section{Contributions of Bacteria in Establishing Epithelial Barrier Function}

Colonization of a germ-free model by B. thetaiotaomicron, a member of the indigenous gut flora, helps establish the epithelial barrier by inducing the expression of Paneth cell proteins (Hooper et al., 2003) and a decay-accelerating factor that facilitates repair (Hooper et al., 2001). Further, the release of indole, a microbial quorum-sensing molecule, has been shown to increase expression of tight junction and adherent junction molecules in the colonic epithelial tissue (Shimada et al., 2013). The increased expression of ZO-2, a tight junction protein, has also been observed following the administration of probiotics, namely E. coli Nissle 1917, both in vitro (Zyrek et al., 2007) and in vivo (Ukena et al., 2007).

In the oral environment, Ye et al. characterized an increase in the expression of tight junction components in oral epithelium following binding of the normal microbiota species S. gordonii (Ye et al., 2013) and identified that binding of these commensals through the CD24 receptor of oral epithelial is responsible for this health associated tissue phenotype (Ye et al., 2014).

Thus, currently, there is minimal evidence in the oral cavity to indicate a role for the indigenous microbiome in affecting tissue phenotype, although emerging evidence suggests that this may an important avenue of investigation.

\section{Contributions of Bacteria to Developing TLRs}

An important link between microbes and epithelial cells in innate immunity is Toll-like receptors (TLRs). Evidence suggest that the expression of TLRs on gut epithelial cells is decreased in germ-free mice when compared to mice with conventional microbiota (Lundin et al., 2008). TLRs respond to both commensals and pathogens, but evidence now suggests TLRs interaction with commensals contributes to intestinal epithelial homeostasis and protection from injury (RakoffNahoum et al., 2004). The location of TLR expression in the gut epithelium has been suggested to play a role in the hosts ability to tolerate commensals and mount a more targeted inflammatory attack against pathogens (Furrie et al., 2005). Evidence also suggests that a benefit of probiotics for maintaining a healthy gut works through the TLR9 pathway, which mediates the anti-inflammatory effects observed with probiotic use (Rachmilewitz et al., 2004). The activation of TLR2 in a stress-induced inflammation model also suppressed mucosal inflammation in the gut by promoting tight junction integrity in the epithelial barrier (Cario et al., 2007). On the skin, commensal Staphylococcal species inhibit skin inflammation through the regulation of TLR3 by Staphylococcal lipoteichoic acid (LTA) activation of a TLR2-dependent pathway (Lai et al., 2009). Subsequently, the activation of TLR2 by Staphylococcus epidermis induces keratinocyte expression of antimicrobial peptides to enhance innate immunity toward pathogens (Lai et al., 2010).

\section{Bacteria and Neutrophil Function}

The cellular components of the innate immune system primarily include neutrophils. Evidence suggests the recruitment of neutrophils to tissue is increased by the presence of the mircobiota (Kanther et al., 2014). Similarly, work from Zenobia et al. has provided evidence that commensal bacteria in the oral cavity selectively upregulate CXCL2 expression leading to an increase in neutrophil recruitment to "prime" healthy gingival tissue (Zenobia et al., 2013). Interleukin-8 is another important chemokine in the innate immune pathway known to attract neutrophils and enhance phagocytosis. The normal microbiota has been shown to induce IL-8 (Darveau et al., 1998; Vankeerberghen et al., 2005), presumably to recruit neutrophils to a potential pathogen colonization site to help prevent overgrowth of pathogens. Not only does the commensal microbiota play a role in recruiting neutrophils, but evidence from a germ-free (Clarke et al., 2010) model suggests that a lack of commensal microbiota reduces phagocytosis and antimicrobial killing activity (Ohkubo et al., 1990, 1999). Commensal bacteria also induce low-level expression of human beta defensins, presumably to keep the innate immune system in a limited activation state (Vankeerberghen et al., 2005) and have been implicated in the regulation of gene expression of the complement system, another important arm of innate immunity (Chehoud et al., 2013).

In summary, a large body of evidence suggests that the host associated microbiome plays an important role in regulating the innate immune system, through epithelial bacterial function, bacterial recognition pathways and signals and innate immune 
cell functions. However, a similar level of evidence is currently lacking in the oral microbiome.

\section{Bacteria and Regulatory T Cell Education}

Although significant evidence exists supporting the role the indigenous microbiota plays in fortifying innate immunity, evidence continues to grow linking commensal microbiota to the adaptive immunity cascade of events. The peripheral education of regulatory $\mathrm{T}$ cells (Treg) in the colon by antigens derived from the commensal microbiota ensures the local tolerance of this microbial community by the host (Lathrop et al., 2011). One well-identified human commensal, Bacteroides fragilis, directs Treg cell education using the immunomodulatory molecule, polysaccharide A (PSA) (Round and Mazmanian, 2010). PSA induces an IL-10 response in T cells that inhibits Th17 expansion preventing future mucosal damage (Round et al., 2011). Similar Treg cell induction and anti-inflammatory effects are seen with colonization of Clostridia species (Atarashi et al., 2011, 2013; Chiba and Seno, 2011; Nagano et al., 2012). In contrast, colonization of the gut intestinal tissue by segmented filamentous bacteria leads to an increase in mature Th17 cells and Th1 cells (Gaboriau-Routhiau et al., 2009; Ivanov et al., 2009).

Similar evidence exists in the oral cavity where members of commensal oral bacteria prime dendritic cells for Th2 and Treg differentiation (Kopitar et al., 2006). Shin et al demonstrated that F. nucleatum, an oral commensal, induces Th1 and Th3 immune responses, while Treponema denticola, a pathogenic species, induced a Th1-dominant response (Shin et al., 2013).

\section{Bacteria and B Cell Education}

Lastly, evidence indicates that commensal microbiota play a role in B cell development and maturation. In human infants, maturation of the mucosal defense system, particularly cells that secrete IgA and IgM, is dependent on the presence of a normal gut flora (Klaasen et al., 1993; Gronlund et al., 2000). This suggests that the development of immune tolerance is dependent on early and sustained exposure to a stable biofilm. Recent evidence suggests that $B$ cell maturation may in fact be dependent on intestinal bacterial colonization as mice colonized early with E. coli and Bifidobacteria have an increased population of CD20+ B cells expressing memory marker CD27 (Lundell et al., 2012). Following development of the lymphoid tissue, the host immune system faces the challenge of finding balance between mounting a swift response toward invading pathogens, but controlling that response against commensals. One way the host controls this response in mice is by using dendritic cells to "sample" the gut lumen and keep live commensals engulfed for a few days to

\section{References}

Aas, J. A., Paster, B. J., Stokes, L. N., Olsen, I., and Dewhirst, F. E. (2005). Defining the normal bacterial flora of the oral cavity. J. Clin. Microbiol. 43, 5721-5732. doi: 10.1128/JCM.43.11.57215732.2005

Abt, M. C., and Pamer, E. G. (2014). Commensal bacteria mediated defenses against pathogens. Curr. Opin. Immunol. 29C, 16-22. doi: 10.1016/j.coi.2014.03.003 selectively induce IgA production (Macpherson and Uhr, 2004). This localized production of IgA helps maintain immune system homeostasis and allows the human host to distinguish between a commensal and pathogenic colonization providing the necessary defense mechanisms to control an infection.

\section{Other Benefits}

Evidence is emerging to suggest that oral bacteria may play a critical role in nitric oxide NO homeostasis (Kapil et al., 2013; Hyde et al., 2014). They do so by reducing dietary nitrate to bioactive NO, a critical symbiotic relationship since humans lack the enzymes to carry out this function. The effects of NO in maintaining cardiovascular integrity are well-established in literature. Thus, recent studies point to a cardio-protective role for oral bacteria; and may provide a critical link in the oralsystemic health connection.

Thus, although the traditional view of an indigenous microbiome is one that provides a nondestructive inflammatory stimulus to the host, thereby ensuring host-bacterial equilibrium, emerging evidence indicates that this community appears to play an active role in developing the host innate immunity and priming the adaptive immune response.

\section{Future Steps}

The role of the microbiome in maintaining health in several human ecosystems is an emerging and exciting field of study. While the health benefits of supporting a large microbial community are actively being explored in reference to the gut, genito-urinary tract, and respiratory system; similarly robust evidence is lacking in relation to the oral microbiome. Several decades of research have been focused on exploring the microbiota associated with oral diseases. While the importance of this quest cannot be downplayed, it is sometimes easy to forget that the ultimate aim of treating disease is to restore health, and the only successful method of preventing disease is by maintaining health. Hence, it is important to focus on the health benefits provided by our microbial fellow travelers and to expend some effort in cataloging and characterizing not only this community, but also the host determinants that play a role in shaping this population.

\section{Funding}

The authors are supported by NIH/NIDCR R01DE022579 (Kumar) and NIH/NIDCR F30DE024940 (Mason).

Adams, D. A., Riggs, M. M., and Donskey, C. J. (2007). Effect of fluoroquinolone treatment on growth of and toxin production by epidemic and nonepidemic clostridium difficile strains in the cecal contents of mice. Antimicrob. Agents Chemother. 51, 2674-2678. doi: 10.1128/AAC.01582-06

Amdekar, S., Singh, V., and Singh, D. (2011). Probiotic therapy: immunomodulating approach toward urinary tract infection. Curr. Microbiol. 63, 484-490. doi: 10.1007/s00284-011-0006-2

Atarashi, K., Tanoue, T., Oshima, K., Suda, W., Nagano, Y., Nishikawa, H., et al. (2013). Treg induction by a rationally selected mixture of Clostridia 
strains from the human microbiota. Nature 500, 232-236. doi: 10.1038/nature 12331

Atarashi, K., Tanoue, T., Shima, T., Imaoka, A., Kuwahara, T., Momose, Y., et al. (2011). Induction of colonic regulatory $\mathrm{T}$ cells by indigenous Clostridium species. Science 331, 337-341. doi: 10.1126/science.1198469

Beraldi-Campesi, H. (2013). Early life on land and the first terrestrial ecosystems. Ecol. Process. 2:1. doi: 10.1186/2192-1709-2-1

Bjorksten, B., Sepp, E., Julge, K., Voor, T., and Mikelsaar, M. (2001). Allergy development and the intestinal microflora during the first year of life. J. Allergy Clin. Immunol. 108, 516-520. doi: 10.1067/mai.2001.118130

Blew, R. D. (1996). On the definition of ecosystem. Bull. Ecol. Soc. Am. 77, 171-173.

Brockhurst, M. A., Colegrave, N., Hodgson, D. J., and Buckling, A. (2007). Niche occupation limits adaptive radiation in experimental microcosms. PLoS ONE 2:e193. doi: 10.1371/journal.pone.0000193

Budtz-Jörgensen, E. (1990). Etiology, pathogenesis, therapy, and prophylaxis of oral yeast infections. Acta Odontol. Scand. 48, 61-69. doi: $10.3109 / 00016359009012735$

Bukowski, J. A., and Lewis, J. (2007). Is the hygiene hypothesis an example of hormesis? Dose Response 1, 4.

Cario, E., Gerken, G., and Podolsky, D. K. (2007). Toll-like receptor 2 controls mucosal inflammation by regulating epithelial barrier function. Gastroenterology 132, 1359-1374. doi: 10.1053/j.gastro.2007.02.056

Chehoud, C., Rafail, S., Tyldsley, A. S., Seykora, J. T., Lambris, J. D., and Grice, E. A. (2013). Complement modulates the cutaneous microbiome and inflammatory milieu. Proc. Natl. Acad. Sci. U.S.A. 110, 15061-15066. doi: 10.1073/pnas.1307855110

Cherry, J. A. (2011). Ecology of wetland ecosystems: water, substrate, and life. Nat. Educ. Knowl. 3:16.

Chiba, T., and Seno, H. (2011). Indigenous clostridium species regulate systemic immune responses by induction of colonic regulatory T cells. Gastroenterology 141, 1114-1116. doi: 10.1053/j.gastro.2011.07.013

Clarke, T. B., Davis, K. M., Lysenko, E. S., Zhou, A. Y., Yu, Y., and Weiser, J. N. (2010). Recognition of peptidoglycan from the microbiota by Nod1 enhances systemic innate immunity. Nat. Med. 16, 228-231. doi: 10.1038/nm.2087

Costandi, M. (2013). Citizen microbiome. Nat. Biotechnol. 31, 90. doi: $10.1038 /$ nbt0213-90a

Costello, E. K., Lauber, C. L., Hamady, M., Fierer, N., Gordon, J. I., and Knight, R. (2009). Bacterial community variation in human body habitats across space and time. Science 326, 1694-1697. doi: 10.1126/science.1177486

Culp, D. J., Robinson, B., Parkkila, S., Pan, P. W., Cash, M. N., Truong, H. N., et al. (2011). Oral colonization by Streptococcus mutans and caries development is reduced upon deletion of carbonic anhydrase VI expression in saliva. Biochim. Biophys. Acta 1812, 1567-1576. doi: 10.1016/j.bbadis.2011.09.006

Darveau, R. P., Belton, C. M., Reife, R. A., and Lamont, R. J. (1998). Local chemokine paralysis, a novel pathogenic mechanism for Porphyromonas gingivalis. Infect. Immun. 66, 1660-1665.

Drenkard, E., and Ausubel, F. M. (2002). Pseudomonas biofilm formation and antibiotic resistance are linked to phenotypic variation. Nature 416, 740-743. doi: $10.1038 / 416740$ a

Fargione, J. E., and Tilman, D. (2005). Diversity decreases invasion via both sampling and complementarity effects. Ecol. Lett. 8, 604-611. doi: 10.1111/j.1461-0248.2005.00753.x

Flint, H. J., Duncan, S. H., Scott, K. P., and Louis, P. (2007). Interactions and competition within the microbial community of the human colon: links between diet and health. Environ. Microbiol. 9, 1101-1111. doi: 10.1111/j.14622920.2007.01281.x

Frank, D. N., Spiegelman, G. B., Davis, W., Wagner, E., Lyons, E., and Pace, N. R. (2003). Culture-independent molecular analysis of microbial constituents of the healthy human outer ear. J. Clin. Microbiol. 41, 295-303. doi: 10.1128/JCM.41.1.295-303.2003

Fredricks, D. N., Fiedler, T. L., and Marrazzo, J. M. (2005). Molecular identification of bacteria associated with bacterial vaginosis. N. Engl. J. Med. 353, 1899-1911. doi: 10.1056/NEJMoa043802

Freter, R., Brickner, H., Botney, M., Cleven, D., and Aranki, A. (1983). Mechanisms that control bacterial populations in continuous-flow culture models of mouse large intestinal flora. Infect. Immun. 39, 676-685.

Furrie, E., Macfarlane, S., Thomson, G., Macfarlane, G. T., Microbiology and Gut Biology Group., et al. (2005). Toll-like receptors-2, -3 and -4 expression patterns on human colon and their regulation by mucosal-associated bacteria Immunology 115, 565-574. doi: 10.1111/j.1365-2567.2005.02200.x

Gaboriau-Routhiau, V., Rakotobe, S., Lecuyer, E., Mulder, I., Lan, A., Bridonneau, C., et al. (2009). The key role of segmented filamentous bacteria in the coordinated maturation of gut helper T cell responses. Immunity 31, 677-689. doi: 10.1016/j.immuni.2009.08.020

Gantois, I., Ducatelle, R., Pasmans, F., Haesebrouck, F., Hautefort, I., Thompson, A., et al. (2006). Butyrate specifically down-regulates Salmonella pathogenicity island 1 gene expression. Appl. Environ. Microbiol. 72, 946-949. doi: 10.1128/AEM.72.1.946-949.2006

Gao, Z., Kang, Y., Yu, J., and Ren, L. (2014). Human pharyngeal microbiome may play a protective role in respiratory tract infections. Genomics Proteomics Bioinformatics 12, 144-150. doi: 10.1016/j.gpb.2014.06.001

Gough, E., Shaikh, H., and Manges, A. R. (2011). Systematic review of intestinal microbiota transplantation (fecal bacteriotherapy) for recurrent Clostridium difficile infection. Clin. Infect. Dis. 53, 994-1002. doi: 10.1093/cid/cir632

Greenblum, S., Turnbaugh, P. J., and Borenstein, E. (2012). Metagenomic systems biology of the human gut microbiome reveals topological shifts associated with obesity and inflammatory bowel disease. Proc. Natl. Acad. Sci. U.S.A. 109, 594-599. doi: 10.1073/pnas.1116053109

Griffen, A. L., Beall, C. J., Campbell, J. H., Firestone, N. D., Kumar, P. S., Yang, Z. K., et al. (2012). Distinct and complex bacterial profiles in human periodontitis and health revealed by 16 S pyrosequencing. ISME J. 6, 1176-1185. doi: 10.1038/ismej.2011.191

Gronlund, M. M., Arvilommi, H., Kero, P., Lehtonen, O. P., and Isolauri, E. (2000). Importance of intestinal colonisation in the maturation of humoral immunity in early infancy: a prospective follow up study of healthy infants aged 0-6 months. Arch. Dis. Child. Fetal Neonatal Ed. 83, F186-F192. doi: 10.1136/fn.83.3.F186

Haffajee, A. D., Teles, R. P., Patel, M. R., Song, X., Yaskell, T., and Socransky, S. S. (2009). Factors affecting human supragingival biofilm composition. II. Tooth position. J. Periodontal Res. 44, 520-528. doi: 10.1111/j.1600-0765.2008.01155.x

He, X., Hu, W., He, J., Guo, L., Lux, R., and Shi, W. (2011). Communitybased interference against integration of Pseudomonas aeruginosa into human salivary microbial biofilm. Mol. Oral Microbiol. 26, 337-352. doi: 10.1111/j.2041-1014.2011.00622.x

Heinemann, C., and Reid, G. (2005). Vaginal microbial diversity among postmenopausal women with and without hormone replacement therapy. Can. J. Microbiol. 51, 777-781. doi: 10.1139/w05-070

Hillman, J. D., Socransky, S. S., and Shivers, M. (1985). The relationships between streptococcal species and periodontopathic bacteria in human dental plaque. Arch. Oral Biol. 30, 791-795. doi: 10.1016/0003-9969(85)90133-5

Hooper, L. V., and Gordon, J. I. (2001). Commensal host-bacterial relationships in the gut. Science 292, 1115-1118. doi: 10.1126/science.1058709

Hooper, L. V., Stappenbeck, T. S., Hong, C. V., and Gordon, J. I. (2003). Angiogenins: a new class of microbicidal proteins involved in innate immunity. Nat. Immunol. 4, 269-273. doi: 10.1038/ni888

Hooper, L. V., Wong, M. H., Thelin, A., Hansson, L., Falk, P. G., and Gordon, J. I. (2001). Molecular analysis of commensal host-microbial relationships in the intestine. Science 291, 881-884. doi: 10.1126/science.291.5505.881

Human Microbiome Project Consortium. (2012). Structure, function and diversity of the healthy human microbiome. Nature 486, 207-214. doi: 10.1038 /nature11234

Hyde, E. R., Andrade, F., Vaksman, Z., Parthasarathy, K., Jiang, H., Parthasarathy, D. K., et al. (2014). Metagenomic analysis of nitrate-reducing bacteria in the oral cavity: implications for nitric oxide homeostasis. PLoS ONE 9:e88645. doi: 10.1371/journal.pone.0088645

Ivanov, I. I., Atarashi, K., Manel, N., Brodie, E. L., Shima, T., Karaoz, U., et al. (2009). Induction of intestinal Th17 cells by segmented filamentous bacteria. Cell 139, 485-498. doi: 10.1016/j.cell.2009.09.033

Jiao, Y., Hasegawa, M., and Inohara, N. (2014). The role of oral pathobionts in dysbiosis during periodontitis development. J. Dent. Res. 93, 539-546. doi: $10.1177 / 0022034514528212$

Joshi, V., Matthews, C., Aspiras, M., de Jager, M., Ward, M., and Kumar, P. (2014). Smoking decreases structural and functional resilience in the subgingival ecosystem. J. Clin. Periodontol. 41, 1037-1047. doi: 10.1111/jcpe.12300

Kalliomaki, M., Salminen, S., Arvilommi, H., Kero, P., Koskinen, P., and Isolauri, E. (2001). Probiotics in primary prevention of atopic disease: 
a randomised placebo-controlled trial. Lancet 357, 1076-1079. doi: 10.1016/S0140-6736(00)04259-8

Kanther, M., Tomkovich, S., Xiaolun, S., Grosser, M. R., Koo, J., Flynn, E. J. 3rd., et al. (2014). Commensal microbiota stimulate systemic neutrophil migration through induction of serum amyloid A. Cell. Microbiol. 16, 1053-1067. doi: $10.1111 / \mathrm{cmi} .12257$

Kapil, V., Haydar, S. M., Pearl, V., Lundberg, J. O., Weitzberg, E., and Ahluwalia, A. (2013). Physiological role for nitrate-reducing oral bacteria in blood pressure control. Free Radic. Biol. Med. 55, 93-100. doi: 10.1016/j.freeradbiomed.2012.11.013

Klaasen, H. L., Van der Heijden, P. J., Stok, W., Poelma, F. G., Koopman, J. P., Van den Brink, M. E., et al. (1993). Apathogenic, intestinal, segmented, filamentous bacteria stimulate the mucosal immune system of mice. Infect. Immun. 61, 303-306.

Kobayashi, N., Ishihara, K., Sugihara, N., Kusumoto, M., Yakushiji, M., and Okuda, K. (2008). Colonization pattern of periodontal bacteria in Japanese children and their mothers. J. Periodontal Res. 43, 156-161. doi: 10.1111/j.16000765.2007.01005.x

Kolenbrander, P. E., Palmer, R. J. Jr., Rickard, A. H., Jakubovics, N. S., Chalmers, N. I., and Diaz, P. I. (2006). Bacterial interactions and successions during plaque development. Periodontol 2000 42, 47-79. doi: 10.1111/j.16000757.2006.00187.x

Kopitar, A. N., Ihan Hren, N., and Ihan, A. (2006). Commensal oral bacteria antigens prime human dendritic cells to induce Th1, Th2 or Treg differentiation. Oral Microbiol. Immunol. 21, 1-5. doi: 10.1111/j.1399302X.2005.00237.X

Kreth, J., Merritt, J., and Qi, F. (2009). Bacterial and host interactions of oral streptococci. DNA Cell Biol. 28, 397-403. doi: 10.1089/dna.2009.0868

Krom, B. P., Kidwai, S., and ten Cate, J. M. (2014). Candida and other fungal species: forgotten players of healthy oral microbiota. J. Dent. Res. 93, 445-451. doi: $10.1177 / 0022034514521814$

Krzeminski, Z., and Raczynska, A. (1993). [Antagonism between oral cavity streptococci and staphylococci]. Med. Dosw. Mikrobiol. 45, 33-36.

Kumar, P. S., Leys, E. J., Bryk, J. M., Martinez, F. J., Moeschberger, M. L., and Griffen, A. L. (2006). Changes in periodontal health status are associated with bacterial community shifts as assessed by quantitative $16 \mathrm{~S}$ cloning and sequencing. J. Clin. Microbiol. 44, 3665-3673. doi: 10.1128/JCM.00 317-06

Kumar, P. S., Matthews, C. R., Joshi, V., de Jager, M., and Aspiras, M. (2011). Tobacco smoking affects bacterial acquisition and colonization in oral biofilms. Infect. Immun. 79, 4730-4738. doi: 10.1128/IAI.05371-11

Kuramitsu, H. K., He, X., Lux, R., Anderson, M. H., and Shi, W. (2007). Interspecies interactions within oral microbial communities. Microbiol. Mol. Biol. Rev. 71, 653-670. doi: 10.1128/MMBR.00024-07

Lai, Y., Cogen, A. L., Radek, K. A., Park, H. J., Macleod, D. T., Leichtle, A., et al. (2010). Activation of TLR2 by a small molecule produced by Staphylococcus epidermidis increases antimicrobial defense against bacterial skin infections. J. Invest. Dermatol. 130, 2211-2221. doi: 10.1038/jid.2010.123

Lai, Y., Di Nardo, A., Nakatsuji, T., Leichtle, A., Yang, Y., Cogen, A. L., et al. (2009). Commensal bacteria regulate Toll-like receptor 3-dependent inflammation after skin injury. Nat. Med. 15, 1377-1382. doi: 10.1038/nm.2062

Lathrop, S. K., Bloom, S. M., Rao, S. M., Nutsch, K., Lio, C. W., Santacruz, N., et al. (2011). Peripheral education of the immune system by colonic commensal microbiota. Nature 478, 250-254. doi: 10.1038/nature10434

Ley, R. E., Hamady, M., Lozupone, C., Turnbaugh, P. J., Ramey, R. R., Bircher, J. S., et al. (2008). Evolution of mammals and their gut microbes. Science 320, 1647-1651. doi: 10.1126/science.1155725

Ley, R. E., Peterson, D. A., and Gordon, J. I. (2006). Ecological and evolutionary forces shaping microbial diversity in the human intestine. Cell 124, 837-848. doi: 10.1016/j.cell.2006.02.017

Li, J., Jia, H., Cai, X., Zhong, H., Feng, Q., Sunagawa, S., et al. (2014). An integrated catalog of reference genes in the human gut microbiome. Nat. Biotechnol. 32, 834-841. doi: 10.1038/nbt.2942

Listgarten, M. A. (1976). Structure of the microbial flora associated with periodontal health and disease in man. A light and electron microscopic study. J. Periodontol. 47, 1-18. doi: 10.1902/jop.1976.47.1.1

Loe, H., Theilade, E., and Jensen, S. B. (1965). Experimental gingivitis in man. J. Periodontol. 36, 177-187. doi: 10.1902/jop.1965.36.3.177

Loesche, W. J. (1982). Dental Caries: a Treatable Infection. Springfield, IL: Charles C. Thomas, c1982.
Loesche, W. J., and Syed, S. A. (1978). Bacteriology of human experimental gingivitis: effect of plaque and gingivitis score. Infect. Immun. 21, 830-839.

Lundell, A. C., Bjornsson, V., Ljung, A., Ceder, M., Johansen, S., Lindhagen, G., et al. (2012). Infant B cell memory differentiation and early gut bacterial colonization. J. Immunol. 188, 4315-4322. doi: 10.4049/jimmunol.1103223

Lundin, A., Bok, C. M., Aronsson, L., Bjorkholm, B., Gustafsson, J. A., Pott, S., et al. (2008). Gut flora, Toll-like receptors and nuclear receptors: a tripartite communication that tunes innate immunity in large intestine. Cell. Microbiol. 10, 1093-1103. doi: 10.1111/j.1462-5822.2007.01108.x

Macpherson, A. J., and Uhr, T. (2004). Induction of protective IgA by intestinal dendritic cells carrying commensal bacteria. Science 303, 1662-1665. doi: 10.1126/science.1091334

Madden, J. A., Plummer, S. F., Tang, J., Garaiova, I., Plummer, N. T., Herbison, M., et al. (2005). Effect of probiotics on preventing disruption of the intestinal microflora following antibiotic therapy: a double-blind, placebo-controlled pilot study. Int. Immunopharmacol. 5, 1091-1097 doi: 10.1016/j.intimp.2005.02.006

Mason, M. R., Nagaraja, H. N., Camerlengo, T., Joshi, V., and Kumar, P. S. (2013). Deep sequencing identifies ethnicity-specific bacterial signatures in the oral microbiome. PLoS ONE 8:e77287. doi: 10.1371/journal.pone.0077287

Nagano, Y., Itoh, K., and Honda, K. (2012). The induction of Treg cells by gut-indigenous Clostridium. Curr. Opin. Immunol. 24, 392-397. doi: 10.1016/j.coi.2012.05.007

Neish, A. S. (2009). Microbes in gastrointestinal health and disease. Gastroenterology 136, 65-80. doi: 10.1053/j.gastro.2008.10.080

Oakley, B. B., Fiedler, T. L., Marrazzo, J. M., and Fredricks, D. N. (2008) Diversity of human vaginal bacterial communities and associations with clinically defined bacterial vaginosis. Appl. Environ. Microbiol. 74, 4898-4909. doi: 10.1128/AEM.02884-07

Ohkubo, T., Tsuda, M., Suzuki, S., El Borai, N., and Yamamura, M. (1999). Peripheral blood neutrophils of germ-free rats modified by in vivo granulocytecolony-stimulating factor and exposure to natural environment. Scand. J. Immunol. 49, 73-77. doi: 10.1046/j.1365-3083.1999.00456.x

Ohkubo, T., Tsuda, M., Tamura, M., and Yamamura, M. (1990). Impaired superoxide production in peripheral blood neutrophils of germ-free rats. Scand. J. Immunol. 32, 727-729. doi: 10.1111/j.1365-3083.1990.tb03216.x

Pace, N. (1997). R. A molecular view of microbial diversity and the biosphere. Science 276, 734-740. doi: 10.1126/science.276.5313.734

Pavia, A. T., Shipman, L. D., Wells, J. G., Puhr, N. D., Smith, J. D., McKinley, T. W., et al. (1990). Epidemiologic evidence that prior antimicrobial exposure decreases resistance to infection by antimicrobial-sensitive Salmonella. J. Infect. Dis. 161, 255-260. doi: 10.1093/infdis/161.2.255

Pepin, J., Saheb, N., Coulombe, M. A., Alary, M. E., Corriveau, M. P., Authier, S., et al. (2005). Emergence of fluoroquinolones as the predominant risk factor for Clostridium difficile-associated diarrhea: a cohort study during an epidemic in Quebec. Clin. Infect. Dis. 41, 1254-1260. doi: 10.1086/496986

Periasamy, S., Chalmers, N. I., Du-Thumm, L., and Kolenbrander, P. E. (2009). Fusobacterium nucleatum ATCC 10953 requires Actinomyces naeslundi ATCC 43146 for growth on saliva in a three-species community that includes Streptococcus oralis 34. Appl. Environ. Microbiol. 75, 3250-3257. doi: 10.1128/AEM.02901-08

Pollard, M., and Sharon, N. (1970). Responses of the Peyer's patches in germ-free mice to antigenic stimulation. Infect. Immun. 2, 96-100.

Prosser, J. I., Bohannan, B. J., Curtis, T. P., Ellis, R. J., Firestone, M. K., Freckleton, R. P., et al. (2007). The role of ecological theory in microbial ecology. Nat. Rev. Microbiol. 5, 384-392. doi: 10.1038/nrmicro1643

Rachmilewitz, D., Katakura, K., Karmeli, F., Hayashi, T., Reinus, C., Rudensky, B., et al. (2004). Toll-like receptor 9 signaling mediates the anti-inflammatory effects of probiotics in murine experimental colitis. Gastroenterology 126, 520-528. doi: 10.1053/j.gastro.2003.11.019

Rakoff-Nahoum, S., Paglino, J., Eslami-Varzaneh, F., Edberg, S., and Medzhitov, R. (2004). Recognition of commensal microflora by toll-like receptors is required for intestinal homeostasis. Cell 118, 229-241. doi: 10.1016/j.cell.2004. 07.002

Rasiah, I. A., Wong, L., Anderson, S. A., and Sissons, C. H. (2005). Variation in bacterial DGGE patterns from human saliva: over time, between individuals and in corresponding dental plaque microcosms. Arch. Oral Biol. 50, 779-787. doi: 10.1016/j.archoralbio.2005.02.001

Round, J. L., and Mazmanian, S. K. (2010). Inducible Foxp3+ regulatory Tcell development by a commensal bacterium of the intestinal microbiota. 
Proc. Natl. Acad. Sci. U.S.A. 107, 12204-12209. doi: 10.1073/pnas.09091 22107

Round, J. L., Lee, S. M., Li, J., Tran, G., Jabri, B., Chatila, T. A., et al. (2011). The Toll-like receptor 2 pathway establishes colonization by a commensal of the human microbiota. Science 332, 974-977. doi: 10.1126/science. 1206095

Sanders, C. C., and Sanders, W. E. Jr. (1982). Enocin: an antibiotic produced by Streptococcus salivarius that may contribute to protection against infections due to group A streptococci. J. Infect. Dis. 146, 683-690. doi: 10.1093/infdis/146.5.683

Savage, D. C. (1977). Microbial ecology of the gastrointestinal tract. Annu. Rev. Microbiol. 31, 107-133. doi: 10.1146/annurev.mi.31.100177.000543

Sepp, E., Julge, K., Mikelsaar, M., and Bjorksten, B. (2005). Intestinal microbiota and immunoglobulin E responses in 5-year-old Estonian children. Clin. Exp. Allergy 35, 1141-1146. doi: 10.1111/j.1365-2222.2005.02315.x

Shea, K., and Chesson, P. (2002). Community ecology theory as a framework for biological invasions. Trends Ecol. Evol. 17, 170-176. doi: 10.1016/S01695347(02)02495-3

Shimada, Y., Kinoshita, M., Harada, K., Mizutani, M., Masahata, K., Kayama, H., et al. (2013). Commensal bacteria-dependent indole production enhances epithelial barrier function in the colon. PLoS ONE 8:e80604. doi: 10.1371/journal.pone.0080604

Shin, J., Kho, S. A., Choi, Y. S., Kim, Y. C., Rhyu, I. C., and Choi, Y. (2013). Antibody and T cell responses to Fusobacterium nucleatum and Treponema denticola in health and chronic periodontitis. PLOS ONE 8:e53703. doi: 10.1371/journal.pone. 0053703

Simon-Soro, A., Belda-Ferre, P., Cabrera-Rubio, R., Alcaraz, L. D., and Mira, A. (2013b). A tissue-dependent hypothesis of dental caries. Caries Res. 47, 591-600. doi: 10.1159/000351663

Simon-Soro, A., Tomas, I., Cabrera-Rubio, R., Catalan, M. D., Nyvad, B., and Mira, A. (2013a). Microbial geography of the oral cavity. J. Dent. Res. 92, 616-621. doi: $10.1177 / 0022034513488119$

Sleator, R. D. (2010). The human superorganism - of microbes and men. Med. Hypotheses 74, 214-215. doi: 10.1016/j.mehy.2009.08.047

Smiley, J. (1978). Plant chemistry and the evolution of host specificity: new evidence from Heliconius and Passiflora. Science 201, 745-747. doi: 10.1126/science.201.4357.745

Socransky, S. S., and Haffajee, A. D. (2005). Periodontal microbial ecology. Periodontol 2000 38, 135-187. doi: 10.1111/j.1600-0757.2005.00107.x

Socransky, S. S., and Manganiello, S. D. (1971). The oral microbiota of man from birth to senility. J. Periodontol. 42, 485-496. doi: 10.1902/jop.1971.42.8.485

Spinillo, A., Capuzzo, E., Acciano, S., De Santolo, A., and Zara, F. (1999). Effect of antibiotic use on the prevalence of symptomatic vulvovaginal candidiasis. Am. J. Obstet. Gynecol. 180, 14-17. doi: 10.1016/S0002-9378(99)70141-9

Sreenivasan, P. K., DeVizio, W., Prasad, K. V., Patil, S., Chhabra, K. G., Rajesh, G., et al. (2010). Regional differences within the dentition for plaque, gingivitis, and anaerobic bacteria. J. Clin. Dent. 21, 13-19.

Sudo, N., Sawamura, S., Tanaka, K., Aiba, Y., Kubo, C., and Koga, Y. (1997). The requirement of intestinal bacterial flora for the development of an IgE production system fully susceptible to oral tolerance induction. J. Immunol. $159,1739-1745$

Teles, R., Teles, F., Frias-Lopez, J., Paster, B., and Haffajee, A. (2013). Lessons learned and unlearned in periodontal microbiology. Periodontol 2000 62, 95-162. doi: 10.1111/prd.12010

Ubeda, C., Taur, Y., Jenq, R. R., Equinda, M. J., Son, T., Samstein, M., et al. (2010). Vancomycin-resistant Enterococcus domination of intestinal microbiota is enabled by antibiotic treatment in mice and precedes bloodstream invasion in humans. J. Clin. Invest. 120, 4332-4341. doi: 10.1172/JCI43918

Ukena, S. N., Singh, A., Dringenberg, U., Engelhardt, R., Seidler, U., Hansen, W., et al. (2007). Probiotic Escherichia coli Nissle 1917 inhibits leaky gut by enhancing mucosal integrity. PLoS ONE 2:e1308. doi: 10.1371/journal.pone.0001308

Van der Hoeven, J. S., and Camp, P. J. M. (1991). Synergistic degradation of mucin by Streptococcus oralis and Streptococcus sanguis in mixed chemostat cultures. J. Dent. Res. 70, 1041-1044. doi: 10.1177/002203459107000 70401

van der Waaij, D., Berghuis-de Vries, J. M., and Lekkerkerk, L.-v. (1971). Colonization resistance of the digestive tract in conventional and antibiotictreated mice. J. Hyg. 69, 405-411. doi: 10.1017/S0022172400021653 van Essche, M., Loozen, G., Godts, C., Boon, N., Pauwels, M., Quirynen, M., et al (2013). Bacterial antagonism against periodontopathogens. J. Periodontol. 84, 801-811. doi: 10.1902/jop.2012.120261

Vankeerberghen, A., Nuytten, H., Dierickx, K., Quirynen, M., Cassiman, J. J., and Cuppens, H. (2005). Differential induction of human beta-defensin expression by periodontal commensals and pathogens in periodontal pocket epithelial cells. J. Periodontol. 76, 1293-1303. doi: 10.1902/jop.2005.76. 8.1293

van Steenbergen, T. J., Bosch-Tijhof, C. J., Petit, M. D., and Van der Velden, U. (1997). Intra-familial transmission and distribution of Prevotella intermedia and Prevotella nigrescens. J. Periodontal Res. 32, 345-350. doi: 10.1111/j.16000765.1997.tb00543.x

Wardwell, L. H., Huttenhower, C., and Garrett, W. S. (2011). Current concepts of the intestinal microbiota and the pathogenesis of infection. Curr. Infect. Dis. Rep. 13, 28-34. doi: 10.1007/s11908-010-0147-7

White, J. F., and Torres, M. S. (2009). Defensive Mutualism in Microbial Symbiosis. Boca Raton, FL: CRC Press. doi: 10.1201/9781420069327

Whorwell, P. J., Altringer, L., Morel, J., Bond, Y., Charbonneau, D., O’Mahony, L., et al. (2006). Efficacy of an encapsulated probiotic Bifidobacterium infantis 35624 in women with irritable bowel syndrome. Am. J. Gastroenterol. 101, 1581-1590. doi: 10.1111/j.1572-0241.2006.00734.x

Wilson, K. H., and Perini, F. (1988). Role of competition for nutrients in suppression of Clostridium difficile by the colonic microflora. Infect. Immun. $56,2610-2614$

Winberg, J., Herthelius-Elman, M., Mollby, R., and Nord, C. E. (1993) Pathogenesis of urinary tract infection-experimental studies of vaginal resistance to colonization. Pediatr. Nephrol. 7, 509-514. doi: 10.1007/BF00852528

Wintermute, E. H., and Silver, P. A. (2010). Dynamics in the mixed microbial concourse. Genes Dev. 24, 2603-2614. doi: 10.1101/gad.1985210

Ximenez-Fyvie, L. A., Haffajee, A. D., and Socransky, S. S. (2000). Comparison of the microbiota of supra- and subgingival plaque in health and periodontitis. J. Clin. Periodontol. 27, 648-657. doi: 10.1034/j.1600-051x.2000.027009648.x

Xu, J., Mahowald, M. A., Ley, R. E., Lozupone, C. A., Hamady, M., Martens, E. C., et al. (2007). Evolution of symbiotic bacteria in the distal human intestine. PLoS Biol. 5:e156. doi: 10.1371/journal.pbio.0050156

Ye, P., Harty, D., Commandeur, Z., and Hunter, N. (2013). Binding of Streptococcus gordonii to oral epithelial monolayers increases paracellular barrier function. Microb. Pathog. 56, 53-59. doi: 10.1016/j.micpath.2012.11.004

Ye, P., Yu, H., Simonian, M., and Hunter, N. (2014). Expression patterns of tight junction components induced by CD24 in an oral epithelial cell-culture model correlated to affected periodontal tissues. J. Periodontal Res. 49, 253-259. doi: $10.1111 /$ jre.12102

Young, K. D. (2006). The selective value of bacterial shape. Microbiol. Mol. Biol. Rev. 70, 660-703. doi: 10.1128/MMBR.00001-06

Zaura, E., Keijser, B. J., Huse, S. M., and Crielaard, W. (2009). Defining the healthy "core microbiome" of oral microbial communities. BMC Microbiol. 9:259. doi: 10.1186/1471-2180-9-259

Zenobia, C., Luo, X. L., Hashim, A., Abe, T., Jin, L., Chang, Y., et al. (2013). Commensal bacteria-dependent select expression of CXCL2 contributes to periodontal tissue homeostasis. Cell. Microbiol. 15, 1419-1426. doi: $10.1111 / \mathrm{cmi} .12127$

Zyrek, A. A., Cichon, C., Helms, S., Enders, C., Sonnenborn, U., and Schmidt, M. A. (2007). Molecular mechanisms underlying the probiotic effects of Escherichia coli Nissle 1917 involve ZO-2 and PKCzeta redistribution resulting in tight junction and epithelial barrier repair. Cell. Microbiol. 9, 804-816. doi: $10.1111 / j .1462-5822.2006 .00836 . x$

Conflict of Interest Statement: The authors declare that the research was conducted in the absence of any commercial or financial relationships that could be construed as a potential conflict of interest.

Copyright (c) 2015 Kumar and Mason. This is an open-access article distributed under the terms of the Creative Commons Attribution License (CC BY). The use, distribution or reproduction in other forums is permitted, provided the original author(s) or licensor are credited and that the original publication in this journal is cited, in accordance with accepted academic practice. No use, distribution or reproduction is permitted which does not comply with these terms. 